This item was submitted to Loughborough's Research Repository by the author.

Items in Figshare are protected by copyright, with all rights reserved, unless otherwise indicated.

\title{
A new friction model in hybrid pump-controlled asymmetric (single-rod) cylinder drive system
}

PLEASE CITE THE PUBLISHED VERSION

https://doi.org/10.1080/10402004.2020.1762955

\section{PUBLISHER}

Informa UK Limited

VERSION

AM (Accepted Manuscript)

\section{PUBLISHER STATEMENT}

This is an Accepted Manuscript of an article published by Taylor \& Francis in Tribology Transactions on 27 Jul 2020, available online: https://doi.org/10.1080/10402004.2020.1762955

\section{LICENCE}

CC BY-NC-ND 4.0

\section{REPOSITORY RECORD}

Wang, Huankun, and Paul Leaney. 2020. "A New Friction Model in Hybrid Pump-controlled Asymmetric (single-rod) Cylinder Drive System”. Loughborough University. https://hdl.handle.net/2134/12789974.v1. 


\section{A new friction model in hybrid pump-controlled asymmetric (single-rod) cylinder drive}

system

Huankun $\mathrm{WANG}^{1}$, Paul G Leaney ${ }^{2}$

${ }^{1}$ Loughborough University, whk430@outlook.com, LE11 3TU, UK

${ }^{2}$ Loughborough University, p.g.leaney@lboro.ac.uk, LE11 3TU, UK

\section{ABSTRACT}

Hybrid pump-controlled asymmetric cylinder drive systems are implemented for energy-saving purposes in applications that do not require fast responses. Under low-velocity and low-pressure conditions, the friction influence in the hybrid pump-controlled system is evident. Researchers have developed various models to describe friction. These friction models are implemented based on the relative motion of the contact surfaces, and they can be categorised into static friction and dynamic friction models. For example, dynamic friction models are suitable for simulating the friction in hydraulic cylinder seals under lubrication conditions. Among the dynamic models, the LuGre model can capture almost all the static and dynamic friction behaviours at the macroscopic level, e.g., stiction, the Stribeck effect, and hysteresis. Thus, the LuGre model is suitable for describing the friction in hydraulic cylinders. As the friction force in the hydraulic cylinder is mainly from the cylinder seal, and the seal deformation occurs under pressure due to its flexibility, the friction in the hybrid pump-controlled hydraulic system is affected by the relative motion of the contact surfaces. Therefore, to investigate factors that affect the friction other than the relative motion of the contact surfaces, the friction behaviours of a hybrid pump-controlled hydraulic system are studied. A pressure difference and acceleration term are introduced in the LuGre 
friction model, and the simulated friction results of the updated LuGre model are compared with the measured experimental results to validate the new friction model.

\section{KEYWORDS}

asymmetric cylinder, friction, Nonlinear analysis, LuGre model, hybrid pump-controlled system, pressure difference, acceleration

\section{INTRODUCTION}

Friction is inevitable in a fluid power system. The majority of friction in a hydraulic system is from the cylinder seals, which is generated from the relative motion of the cylinder piston. The primary friction behaviours are depicted in Figure 1.

Figure 1(a) describes the Coulomb friction, which is a constant that depends on the degree of roughness of the contacting surfaces and the normal load. Figure 1(b) illustrates the viscous friction, which is proportional to the velocity. As shown in Figure 1(c), the Stribeck effect introduces friction at low speeds, and the friction decreases exponentially with increasing speed. Figure 1(d) combines all three friction behaviours in Figure 1(a)-(c), and it shows the primary friction behaviours over a range of velocities [1].

As the hydraulic fluid oil plays a lubrication role, there are four regimes illustrated in Figure 2, which are static friction, boundary lubrication, partial fluid lubrication, and full fluid lubrication. An oil film layer is partially formed in the third regime and is fully formed between the contact surfaces in the fourth regime [2]. The acceleration and deceleration affect the oil film layer's formation and thickness [3], which leads to friction lag and hysteresis behaviours. Various friction models are proposed to simulate friction behaviours. They can be classified into two types: static and dynamic models [4]. The significant difference between the two types is that the static model 
does not include pre-sliding displacement, which occurs at the contact interface. Therefore, picking a proper friction model for the corresponding design is necessary, and it can help to improve the simulation performance and system control.

A typical static model is the classical friction model, which includes stiction friction, Coulomb friction, and viscous friction [5]. This model relates the friction force to the velocity and uses a discontinuity at zero velocity to explain the direction change of the Coulomb friction. In this model, the friction can be any value between the Coulomb friction limits at zero velocity. This simple classical model introduces problems in simulations when the velocity crosses zero. Karnopp overcame this problem [6] by introducing a small velocity zone as the 'stick' state, during which the stiction friction force exactly cancels the external driving force. After the driving force exceeds the 'break free' force value, the system begins to accelerate. When the magnitude of the velocity is outside the velocity zone, the system switches from 'stick' to 'slip'. Although the model solves the zero-crossing problem, the complexity of the model increases as more masses are added to the system [7]. A continuous velocity-based friction model is proposed to solve the discontinuity problem [8]. The original bristle model is extended to a three dimensional model for general contact dynamics modelling [9]. These friction models are typical static friction models, and they do not include pre-sliding displacement, unlike the dynamic models.

One of the first dynamic models is created by Dahl [10] [11]. The Dahl model is based on experimental work for ball bearings. The pre-sliding displacement is interpreted as the elastic deformation of surface asperities, which is referred to as the Dahl effect.

Although the Dahl model is simple to use, it does not include stiction or the Stribeck effect. The bristle model was constructed by Hassig [12], which modelled the contacting asperities on the 
surface. In this model, rigid bristles are attached to one surface, and elastic bristles are attached to the other surface, as shown in Figure 3, where $z$ denotes the average deflection of the bristles. The sum of the restoring forces acting on the elastic bristles is regarded as the friction force.

\section{The LUGRE MODEL}

Based on the bristle model, the LuGre model was proposed [13]. This model is simple and includes the most friction phenomena. It captures hysteresis-like behaviours, including friction lag and spring-like characteristics during stiction and stick-slip behaviour when velocity reversals occur [14].

Other friction models have been proposed that improved the LuGre model, like the Generalized Maxwell-slip model [15] and the Leuven integrated friction model [16] [17]. A modified LuGre model is used to simulate the friction force in a pendulum in the pre-sliding state [18]. However, most of these models focus on pre-sliding and hysteretic phenomena, which occur over a small displacement range (unit: $\mu \mathrm{m}$ ). However, most hydraulic devices cannot operate under such a small displacement ranges, so the LuGre model is the best choice of the friction models to simulate friction in hydraulic cylinders.

The asperity junctions used in the LuGre model are considered to be bristles, as illustrated in Figure 5. The average deflection of the bristles $z$ is expressed as follows:

$$
\frac{d z}{d t}=v-\sigma_{0} \frac{z}{g(v)}|v|
$$

where $v$ is the relative velocity, $g(v)$ is used to describe the Stribeck effect, and $\sigma_{0}$ is the average stiffness of the bristles. A parameterised expression for $g(v)$ can be written as follows: 


$$
g(v)=F_{C}+\left(F_{S}-F_{C}\right) e^{-\left(v / v_{S}\right)^{2}}
$$

where $F_{C}$ is the Coulomb friction, $F_{S}$ is the Stiction friction, and $v_{S}$ is the Stribeck velocity. The overall friction force is expressed as follows:

$$
F_{f}=\sigma_{0} z+\sigma_{1} \frac{d z}{d t}+\sigma_{2} v
$$

where $\sigma_{0}$ is the average stiffness of the bristle, $\sigma_{1}$ is a micro-viscous coefficient that is equivalent to a damping coefficient, and $\sigma_{2}$ is the viscous coefficient.

When the velocity is at the steady state, the average bristle deflection $z$ becomes

$$
z_{S S}=\frac{g(v)}{\sigma_{0}} \operatorname{sgn}(v)
$$

where

$$
\operatorname{sgn}(v)=\left\{\begin{array}{cc}
1 & \text { if } v>0 \\
0 & \text { if } v=0 \\
-1 & \text { if } v<0
\end{array}\right.
$$

As the velocity is constant at the steady state, $\frac{d z}{d t}$ must equal zero. Thus, the overall friction force at the steady state is as follows:

$$
F_{f s s}=\sigma_{0} z_{s s}+\sigma_{2} v
$$

Substituting $z_{s s}$ and $g(v)$ into the steady-state friction force equation yields the following:

$$
F_{f s s}=\operatorname{sgn}(v)\left[F_{C}+\left(F_{S}-F_{C}\right) e^{-\left(\frac{v}{v_{s}}\right)^{2}}\right]+\sigma_{2} v
$$

A new mathematical model based on the LuGre model is proposed to investigate the hysteresis phenomenon in pneumatic cylinders [19], which indicates the LuGre model is an appropriate choice to simulate the friction force in a cylinder. 


\section{HYBRID PUMP-CONTROLLED ASYMMETRIC CYLINDER DRIVE SYSTEM}

The hybrid pump-controlled system contains a servo motor coupled with a bi-directional gear pump, an oversized pilot directional four-way valve that only operates at the maximum opening (eliminating throttle losses), three pressure-relief valves, a needle valve (increases stability), an asymmetric cylinder drive, pressure transducers, and a potentiometer. Therefore, this hybrid pumpcontrolled system combines the advantages and disadvantages of valve-controlled and pumpcontrolled systems. The system is depicted in Figure 4, and the test rig is shown in Figure 5.

The flow in the hybrid pump-controlled hydraulic system must be balanced during operation. The flow rate is larger when the cylinder is extending than when it is retracting for a constant pump velocity. In addition, the stability can be an issue if some conditions are met [20]. The performance characteristics of the hybrid pump-controlled systems are discussed elsewhere [21].

The oversized four-way valve in Figure 4 is able to reduce throttle losses as much as possible and provides a good load-holding performance, and the detailed system analysis is discussed elsewhere [22].

Pressure transducers were used to measure the asymmetric cylinder chamber pressures $P_{1}$ and $P_{2}$, as shown in Figure 4. The potentiometer records the displacement information of the asymmetric cylinder, and the cylinder velocity $v$ is the derivative of its displacement. Its acceleration is the derivative of the velocity.

The asymmetric cylinder drive system is shown in Figure 5. Its asymmetric cylinder was placed on an iron plate, a tray was coupled with the end of the cylinder rod, and loads could be added to the system. 
Although the friction force $F_{f}$ is not measurable, it can be calculated as follows:

$$
F_{f}=P_{1} A_{1}-P_{2} A_{2}-m a
$$

where $A_{1}$ is the cylinder piston area, $A_{2}$ is the rod side area, $P_{1}$ is the measured piston side chamber pressure, $P_{2}$ is the measured rod side chamber pressure, $m$ is the attached mass (including the load, tray, and cylinder rod), and $a$ is the acceleration. All the measured signals were filtered by a $5 \mathrm{~Hz}$ low pass filter. Further details can be found elsewhere [22].

\section{Cylinder piston seal}

The asymmetric cylinder in the hybrid pump-controlled asymmetric cylinder drive system was obtained from [22], and its piston seal is depicted in Figure 6. As the seal was constructed of nitrile rubber flexible material as the inner ring in Figure 7, its deformation occurs when fluid pressure applies on the outer ring, leads to a squeeze effect between the inner ring and the cylinder sleeve, and affects the seal contact pressure.

The seal friction $F_{\text {seal }}$ is proportional to the effective contact pressure [24], expressed as follows:

$$
F_{\text {seal }}=\mu(v) P_{e} \cdot A
$$

where $\mu$ is the coefficient of friction, $P_{e}$ is the effective contact pressure, $v$ is the rubbing velocity, and $A$ is the seal contact area. The friction coefficient $\mu$ is an empirical factor that varies with factors, such as speed, time, material, and surface roughness. The H-shaped piston seal shown in Figure 6 is flexible and deforms under pressure. This shape design ensured that the seal was always in contact with the piston sleeve surface. This type of seal is called a pressure-energised seal, and it is prone to extrusion and wedging under high pressure. Under this circumstance, the friction force increases considerably, and its value is proportional to the square of the effective pressure [24], which is expressed as follows: 


$$
F_{\text {seal }}=\delta \cdot \mu(v) \cdot\left(P_{e}\right)^{2} A
$$

where $\delta$ is a constant based on the type of the seal. The contact area $A$ will be affected by the pressure applied on the seal, and the coefficient $\mu$ is an empirical factor. The above parameters are affected by various conditions, and they are very difficult to measure. In addition, the effective contact pressure $P_{e}$ is composed of a pre-loading pressure $P_{\text {preload }}$ and the pressure difference between both sides of the piston seal $P_{d}$ [24]. The pre-loading pressure $P_{\text {preload }}$ was not measurable in the hybrid pump-controlled system, and the pressure difference $P_{d}$ has a great influence on the effective contact pressure $P_{e}$. Thus, the seal friction can be expressed as follows:

$$
F_{\text {seal }}=K\left(P_{d}\right)^{2} v
$$

The gain $K$ is not only composed of the coefficient $\mu$ and contact area $A$ but also accounts for the contact pressure $P_{e}$ and pressure difference $P_{d}$. A revised LuGre model is proposed to research the fluid lubrication influence in friction force and adds an acceleration term in the LuGre model [25].

\section{THEORY and EXPERIMENT}

\section{New friction model}

In this hybrid pump-controlled asymmetric cylinder system, the cylinder piston seal is a pressureenergised type, but the rod seal and wiper seal are not under pressure during system operation, and they are equivalent to a simple lubricated contacting surface. Thus, the friction of the rod and wiper seal should be expressed by velocity functions. The load coupled to the cylinder moves horizontally on a plate, and its friction should also be expressed by a velocity function.

As the LuGre model is a well-established friction model based on velocity and the energypressurised seal friction is not a complex function, a new friction model based on the LuGre model is defined as follows: 


$$
\begin{gathered}
F_{f}=\sigma_{0} z+\sigma_{1} \frac{d z}{d t}+K\left[\left(P_{1}-P_{2}\right)^{2} v+H \cdot a\right] \\
\frac{d z}{d t}=v-\sigma_{0} \frac{z}{g(v)}|v| \\
g(v)=F_{C}+\left(F_{S}-F_{C}\right) e^{-\left(v / v_{S}\right)^{2}}
\end{gathered}
$$

During low velocity, stick-slip and Stribeck effects are mainly described by $\sigma_{0} z+\sigma_{1} \dot{z}$. When the system is in the normal operation state, the pressure-energised seal friction component $K\left(P_{d}\right)^{2} v$ will show its distinct influence. The acceleration term $K \cdot H \cdot a$ is a key part of the friction force in dynamics, where $H$ is an acceleration coefficient. This new friction model should able to capture both micro- and macro-friction behaviours for hydraulic cylinders. There are several parameters that must be identified to complete the model, as discussed in the next section.

\section{Model parameter identification}

A new friction model was proposed in the last section, and its parameters vary due to various factors, for example, the contacting surface roughness, load, and lubrication conditions. For the hybrid pump-controlled asymmetric cylinder system, there are a unique set of parameters for the

new friction model, as summarized in Table 1. This section presents the procedures for the identification of all the parameters.

\section{Model parameters in steady state}

The procedures for the identification of the parameters when the system was in steady and dynamic states are presented in this section. Several tests were conducted to identify these parameters. The first step was to find the values of the parameters when the asymmetric cylinder was in steady state. 
A square wave command was sent to the system to perform a symmetric velocity square wave movement, and the pressure transducers recorded the chamber pressures $P_{1}$ and $P_{2}$. The potentiometer recorded the displacement of the cylinder in real-time. The cylinder velocity was obtained as follows:

$$
v_{i}=\frac{l_{i}-l_{i-1}}{t_{\text {interval }}}
$$

where $t_{\text {interval }}$ is the time interval of each recorded displacement data point, $l$ is the displacement of the cylinder, subscript $i$ indicates the $i^{\text {th }}$ data point. During the square wave tests, the friction force was in steady state. In the new friction model, this is expressed as follows:

$$
F_{f S S}=\operatorname{sgn}(v)\left[F_{C}+\left(F_{S}-F_{c}\right) e^{-\left|\frac{v}{v_{s}}\right|^{\alpha}}\right]+K\left(P_{d}\right)^{2} v
$$

The friction force was calculated by Equation (7). However, during steady state, the acceleration $a$ was equal to zero. The measured friction force in the steady state becomes the following:

$$
F_{f}=P_{1} A_{1}-P_{2} A_{2}
$$

For example, a biased square wave command is sent to the asymmetric cylinder to perform a $\pm 25 \mathrm{~mm} / \mathrm{s}, 0.2 \mathrm{~Hz}$ square wave motion, the chamber pressure $P_{1}$ and $P_{2}$ were measured by transducers, and the friction force was calculated using Equation (14). The steady-state friction forces from the experimental measurements are shown in Figure 8.

The steady-state friction force was obtained by averaging the friction values when the cylinder was in the steady-state region, as shown in Figure 8. More square wave velocity inputs were sent to the test rig to measure the friction force under different velocities. The steady-state friction forces and corresponding velocities are summarized in Table 2 . 
There were friction force values corresponding to a zero velocity. This phenomenon was due to the cylinder being in a stiction state. The steps of the no-added-load test can be summarised as follows:

- Disconnect the tray and cylinder.

- Send a biased square signal to the system to perform a symmetric square wave motion on the asymmetric cylinder.

- Record the peak (stiction friction) and steady-state friction force.

- Repeat the above processes with different cylinder square wave tests and draw the steadystate friction force curve, as shown in Figure 9.

Thus, the steady-state friction with different velocities curves is shown in Figure 9.

The right half of this curve corresponds to when the cylinder was in extending mode, and the left half was when the cylinder was in retracting mode. In both modes, the stiction, Stribeck effect, and viscous friction were evident. When the asymmetric cylinder began its motion, the friction force reached the maximum stiction friction force. At a low cylinder velocity, the friction force decreased with increased velocity. After the velocity exceeded a threshold, the friction force increased with increased velocity.

When the asymmetric cylinder operated at the same absolute velocity, the absolute friction force in the extending state was larger than that in the retracting state. This phenomenon was caused by the piston area difference. When the cylinder was retracting, a lower flow rate was required to achieve the same velocity as that in the extending state, and thus, the pressure in the rod side 
chamber was smaller. The difference was also evident in the pressure-energised piston seal, and a smaller compression pressure led to a smaller friction force.

The measured steady-state friction force curves were observed, and some of the parameters' values are shown in Table 3, which indicates that the parameters $F_{c}$ and $F_{S}$ are different in cylinder extending and retracting states. So that the $g(v)$ in equation (11) can be updated as below:

$$
g(v)= \begin{cases}F_{C e}+\left(F_{S e}-F_{C e}\right) e^{-\left(v / v_{S e}\right)^{2}} & v \geq 0 \\ F_{C r}+\left(F_{S r}-F_{C r}\right) e^{-\left(v / v_{S r}\right)^{2}} & v<0\end{cases}
$$

$F_{C e}$ is the Coulomb friction when cylinder in extending state, $F_{S e}$ is the Stick friction in extending state, $F_{C r}$ is the Coulomb friction when cylinder in retracting state and $F_{S r}$ is the Stick friction in retracting state. $v_{s e}$ is the Stribeck velocity in extending state and $v_{s r}$ is the Stribeck velocity in retracting state.

With the data collected in Table 2, the steady-state friction force (Equation (13)) and measured values in Table 3 were input into curve fitting tools (CFTOOL) in MATLAB. The obtained parameter values are summarized in Table 4.

Substituting these values into the new friction model equations yielded the simulated friction force. The measured friction curve and simulated data at steady state are compared in Figure 10, indicating that the new friction model was able to capture the friction behaviours in the hybrid pump-controlled asymmetric cylinder drive system when it was at steady state.

The steady-state friction curve generated by the new friction model can capture the stiction, Stribeck effect, and viscous friction phenomena. 


\section{Model parameters in dynamics}

The stiffness $\sigma_{0}$ and micro-damping $\sigma_{1}$ are related to the friction force dynamics. In the new friction model, they are combined with the average bristle deformation $z$. The derivative of the average deformation $z$ is not zero when the velocity of the asymmetric cylinder continually changes. To identify the values of $\sigma_{0}$ and $\sigma_{1}$, a $0.2 \mathrm{~Hz}$ sinusoidal wave was sent to the system to make the asymmetric cylinder perform sine wave motion with a $\pm 50 \mathrm{~mm} / \mathrm{s}$ amplitude.

The measured dynamic friction force for the $0.2 \mathrm{~Hz}$ sinusoidal wave is shown in Figure 11. Some spikes are evident when the asymmetric cylinder changed its direction. The spikes were typically due to a stiction friction phenomenon combined with the cylinder dynamics. The pressure accumulated until the pressure difference was large enough to overcome the stiction force. When the piston began to move, the chamber pressure suddenly dropped to some level. The pressure drop also affected the friction force, shown as a spike in Figure 11.

With the known parameters, guess values for $\sigma_{0}$ and $\sigma_{1}$ were selected, as shown in Table 5, these guess values were picked from a similar test rig [26].

The value of the bristle stiffness $\sigma_{0}$ affects the magnitudes and rise time of the break-away force [27]. The values of $\sigma_{0}$ and $\sigma_{1}$ were adjusted until the simulated curve matched the experimental results. The values are shown in Table 6.

The parameters in Table 3, 4, and 6 were used to simulate the friction with the original LuGre model, and the simulation results are compared to the experimental results in Figure 11. The coefficient of determination $\left(R^{2}\right)$ is used to assess the the accuracy of modelling results. The range of the $R^{2}$ is from 0 to 1 , larger value indicates better model accuracy. The $R^{2}$ of the test in Figure 11 is 0.8938 . A comparison of the friction force vs velocity curves is shown in Figure 12. 
The LuGre model did not capture the experimental behaviour well, and many of the dynamic and transient behaviours were not captured.

\section{RESULTS}

\section{Pressure difference term influence}

It was assumed that the new friction model does not include an acceleration factor, expressed as follows:

$$
\begin{gathered}
F_{f}=\sigma_{0} z+\sigma_{1} \frac{d z}{d t}+K\left(P_{1}-P_{2}\right)^{2} v \\
\frac{d z}{d t}=v-\sigma_{0} \frac{z}{g(v)}|v| \\
g(v)= \begin{cases}F_{C e}+\left(F_{S e}-F_{C e}\right) e^{-\left(v / v_{s e}\right)^{2}} & v \geq 0 \\
F_{C r}+\left(F_{S r}-F_{C r}\right) e^{-\left(v / v_{s r}\right)^{2}} & v<0\end{cases}
\end{gathered}
$$

The experimental results are compared with the friction model given by Equation (17) in Figure 13. Overall, the friction model is given by Equation (17) almost captures the dynamics observed in the experiments with a better $R^{2}$ value 0.8983 , but the simulated friction did not catch up with the force when the cylinder changed its direction. This is evident in the friction force vs velocity plot shown in Figure 14.

\section{Acceleration term influence}

The friction model given by Equation (17) improved the agreement with the experimental results after the direction of the velocity was reversed, as shown in Figure 13. However, the friction force during the switching was not captured, as shown in Figure 14. This phenomenon was related to the fluid film thickness change during the piston acceleration and deacceleration [1], which means 
there should be an acceleration term in the new friction model. To compensate for this difference, the proposed friction model expressed by Equation (11) was used.

$H$ in Equation (11) can be regarded as a gain. The CFTOOL in MATLAB revealed that when the cylinder was extending, $H=3.046 \times 10^{9} \mathrm{~N}^{2} / \mathrm{m}^{5}$, while when it was retracting, $H=9 \times$ $10^{9} \mathrm{~N}^{2} / \mathrm{m}^{5}$. Substituting values of $H$ into the new friction model, the comparison with the experimental results is shown in Figure 15 and Figure 16.

The new friction model with the pressure difference and acceleration terms captured the dynamics of the friction better during the system operation. For the asymmetric cylinder drive system studied herein, the new friction model parameters are listed in Table 7.

Based on Figure 15 and Figure 16, although the new friction model was unable to capture all the friction results from the experiment perfectly and some transient changes were not reproduced, it was nearly consistent with the experimental results with a $R^{2}$ value of 0.9032 . Thus, the new friction model was successful. These parameters in Table 7 were obtained without a load applied to the cylinder. The load influence is discussed in the next section.

\section{Added load test}

The tests above were carried out without any load. In theory, the load should only the affect stiction friction $F_{s}$ and Coulomb friction $F_{c}$ [27]. Two loaded tests were carried out to verify this assumption. The first test used a $25 \mathrm{~kg}$ load (tray and added load) attached to the asymmetric cylinder. The same $0.2 \mathrm{~Hz}$ sinusoidal wave was sent to the cylinder to perform the same sine wave motion as that in the no-added-load tests. 
The values of the parameters were kept the same as they were in the previous sections, except for those of the stiction friction $F_{S}$ and Coulomb friction $F_{c}$, whose adjusted values are shown in Table 8. The new friction model Equation (11) was used and compared with the measured friction force, as shown in Figure 17. The $R^{2}$ value of the test is 0.9231 .

As shown in Figure 18, the new friction model was still able to capture almost all the experimental friction behaviours under the loaded condition.

A further test was carried out with a $38 \mathrm{~kg}$ load (tray and added load) attached to the asymmetric cylinder, and the corresponding stiction friction $F_{S}$ and Coulomb friction $F_{c}$ are shown in Table 9.

The friction force from the model is compared with the experimental results in Figure 19. The $R^{2}$ value of the test is 0.5711 , the value is lower due to the highly negative peak of experimental results when the test starts to run. The highly negative peak may be caused by the initial fluid pressure charging process. Some air may be trapped around the transducers, so the 'wrong' data was recorded. Once the fluid was pressurized, the air was dissolved into the fluid oil, and the following data was reasonable. The actual reason will be investigated in the future. The rest simulated curve showed good consistency with the experimental results.

The friction force vs velocity curves are shown in Figure 20. Although some transient behaviours were not captured, the new friction model captured almost all the friction behaviours in the hybrid pump-controlled asymmetric cylinder drive system. Thus, the assumption that the external load only affected the parameters $F_{C}$ and $F_{S}$ was verified. However, the values of both parameters were not significantly changed with different added loads, and this may have been because the added load was already reflected in the pressure term of the new friction model. Higher pressure affects the contact pressure of the seal and increases the value of the friction force. For the pump- 
controlled system with a certain load, the speed is controlled by the pump only, and a higher steady state velocity normally indicates a higher pressure and larger friction force. All these tests were carried out in a low-velocity scenario, the performance of this new friction model under high velocities will be tested in future.

\section{CONCLUSIONS}

The friction behaviours in a hybrid pump-controlled asymmetric cylinder drive system were investigated, and a new friction model was developed based on the original LuGre model, the original LuGre model is as follows:

$$
\text { Orignal LuGre model }\left\{\begin{array}{c}
F_{f}=\sigma_{0} z+\sigma_{1} \frac{d z}{d t}+\sigma_{2} v \\
\dot{z}=v-\sigma_{0} \frac{z}{g(v)}|v| \\
g(v)=F_{c}+\left(F_{s}-F_{c}\right) e^{-\left(v / v_{s}\right)^{\alpha}}
\end{array}\right.
$$

The new friction model combines the friction calculation with the velocity, chamber pressure, and acceleration. The new friction model, which can be used for hydraulics applications, is as follows:

$$
\text { New friction model }\left\{\begin{array}{c}
F_{f}=\sigma_{0} z+\sigma_{1} \dot{z}+K\left[\left(P_{1}-P_{2}\right)^{2} v+H \cdot a\right] \\
\dot{z}=v-\sigma_{0} \frac{|v|}{g(v)} z \\
g(v)= \begin{cases}F_{C e}+\left(F_{S e}-F_{C e}\right) e^{-\left(v / v_{s e}\right)^{2}} & v \geq 0 \\
F_{C r}+\left(F_{S r}-F_{C r}\right) e^{-\left(v / v_{s r}\right)^{2}} & v<0\end{cases}
\end{array}\right.
$$

Compared with the original LuGre model, some new parameters were introduced. The $K\left[\left(P_{1}-P_{2}\right)^{2} v\right]$ component added the pressure influence in the $\sigma_{2} v$ part of the original LuGre model. The $K H \cdot a$ component describes the influence of the acceleration. As the parameters $K$ and $H$ were obtained by a curve-fitting method, the new friction model is an empirical model. 
The calculated friction results were compared with experimental results when an asymmetric cylinder performed $\pm 50 \mathrm{~mm} / \mathrm{s}$ sine wave motion. This validated its ability to describe the friction force in a hybrid pump-controlled asymmetric cylinder drive system. Compared with the simulation results from the original LuGre friction model, the improvements in accuracy and consistency of the new friction model were validated.

The new friction model was developed for low-velocity and low-pressure conditions, and to research the fluid pressure, velocity and acceleration influence on the friction force. The pressure difference is asymmetric with symmetric signal input as the actuator in the system is an asymmetric cylinder, which leads to the asymmetry of the new friction model. Further investigations can be carried out under high-velocity, high-pressure working conditions with different types of seal to validate and improve the new friction model for various operating conditions.

\section{REFERENCES}

[1] M. Hvoldal, "Friction modelling and parameter estimation for hydraulic asymmetrical cylinders," Aalborg University, 2011.

[2] Márton, L. and Lantos, B., "Identification and model-based compensation of Striebeck friction," Acta Polytechnica Hungarica, pp. 3(3), pp. 45-58., 2006.

[3] E. Rabinowicz, "The intrinsic variables affecting the stick-slip process," in Proceedings of the Physical Society, 1958.

[4] Marques, Filipe, Paulo Flores, J. C. Pimenta Claro, and Hamid M. Lankarani. (2016). “A Survey and Comparison of Several Friction Force Models for Dynamic Analysis of Multibody Mechanical Systems." Nonlinear Dynamics 86(3): 1407-43. 
[5] A. F. G. a. M. G. Bonsignore, "Analytical formulation of the classical friction model for motion analysis and simulation," Mathematical \& Computer Modelling of Dynamical Systems, pp. 5(1), pp. 43-54., 1999.

[6] D. Karnopp, "Computer simulation of stick-slip friction in mechanical dynamic systems," ASME Journal of Dynamic Systems Measurement and Control, pp. 107(1), 100-103., 1985.

[7] Pennestrì, Ettore, Valerio Rossi, Pietro Salvini, and Pier Paolo Valentini. 2016. "Review and Comparison of Dry Friction Force Models." Nonlinear Dynamics 83(4): 1785-1801.

[8] Brown, Peter, and John McPhee. 2016. “A Continuous Velocity-Based Friction Model for Dynamics and Control with Physically Meaningful Parameters." Journal of Computational and Nonlinear Dynamics 11(5): 1-6.

[9] Liang, Jianxun, Steven Fillmore, and Ou Ma. 2012. "An Extended Bristle Friction Force Model with Experimental Validation.” Mechanism and Machine Theory 56: 123-37.

[10] Dahl.P.R., "A solid friction model," Aerospace corporation, El Segurdo, California, USA, 1968.

[11] Dahl.P.R, "Measurement of solid friction parameters of ball bearings," 1977.

[12] Haessig, D. A. and Friedland, B., "On the Modeling and Simulation of Friction," 1990.

[13] C. C. De Wit, H. Olsson, K.J. strm and P. Lischinsky, "A new model for control of systems with friction," IEEE Transactions on Automatic Control, vol. 40, no. 3, p. 419-425, 1995. 
[14] Marques, Filipe, Paulo Flores, J. C.Pimenta Claro, and Hamid M. Lankarani. 2019. "Modeling and Analysis of Friction Including Rolling Effects in Multibody Dynamics: A Review.” Multibody System Dynamics 45(2): 223-44.

[15] Al-Bender, F., Lampaert, V. and Swevers, J., "The generalized Maxwell-slip model: A novel model for friction simulation and compensation," IEEE Transactions on Automatic Control, vol. 50, no. 11, p. 1883-1887, 2005.

[16] Jan Swevers, Farid Al-Bender, Chris G. Ganseman, and Tutuko Prajogo, "An integrated friction model structure with improved presliding behavior for accurate friction compensation," IEEE TRANSACTIONS ON AUTOMATIC CONTROL, vol. 45, no. 4, pp. 675-686, 2000.

[17] Lampaert, V., Swevers, J. and Al-Bender, F., "Modification of the Leuven integrated friction model structure," IEEE Transactions on Automatic Control, vol. 47, no. 4, p. 683$687,2002$.

[18] Piatkowski, T., and M. Wolski. 2018. "Analysis of Selected Friction Properties with the Froude Pendulum as an Example.” Mechanism and Machine Theory 119: 37-50.

[19] Tran, X. B., H. T. Dao, and K. D. Tran. 2016. “A New Mathematical Model of Friction for Pneumatic Cylinders.” Proceedings of the Institution of Mechanical Engineers, Part C: Journal of Mechanical Engineering Science 230(14): 2399-2412. 
[20] Wang, L., Book, W. J. and Huggins, J. D., "A Hydraulic Circuit for Single Rod Cylinders," Journal of Dynamic Systems, Measurement, and Control, vol. 134, no. 1, pp. 011-019, 2012.

[21] Quan, Z. Quan, L, Zhang, J, "Review of energy efficient direct pump controlled cylinder electro-hydraulic technology," Renewable and Sustainable Energy Reviews, vol. 35, pp. 336-346, 2014.

[22] H. Wang, "Improved modelling and driving of hydraulic asymmetric cylinders systems (Thesis)," Loughborough University, Loughborough, 2018.

[23] APH, "C10 18 series cylinder data sheet," [Online]. Available: http://www.aph.co.uk/wpcontent/uploads/2017/04/APH-C10-Brochure.pdf.

[24] M. Brown., Seals \& sealing hand book, Fourth edition ed., Elsevier science publishers LTD, 1995.

[25] Bo Tran, Xuan, Van Lai Nguyen, and Khanh Duong Tran. 2019. "Effects of Friction Models on Simulation of Pneumatic Cylinder.” Mechanical Sciences 10(2): 517-28.

[26] Yanada, H., Takahashi, K. and Matsui, A., "Identification of Dynamic Parameters of Modified LuGre Model and Application to Hydraulic Actuator," TRANSACTIONS OF THE JAPAN FLUID POWER SYSTEM SOCIETY, vol. 40, no. 4, p. 57-64, 2009.

[27] Tran, X. B., Hafizah, N. and Yanada, H., "Modeling of dynamic friction behaviors of hydraulic cylinders," Mechatronics Elsevier Ltd, vol. 22, no. 1, p. 65-75, 2011. 


\section{TABLES AND FIGURES}
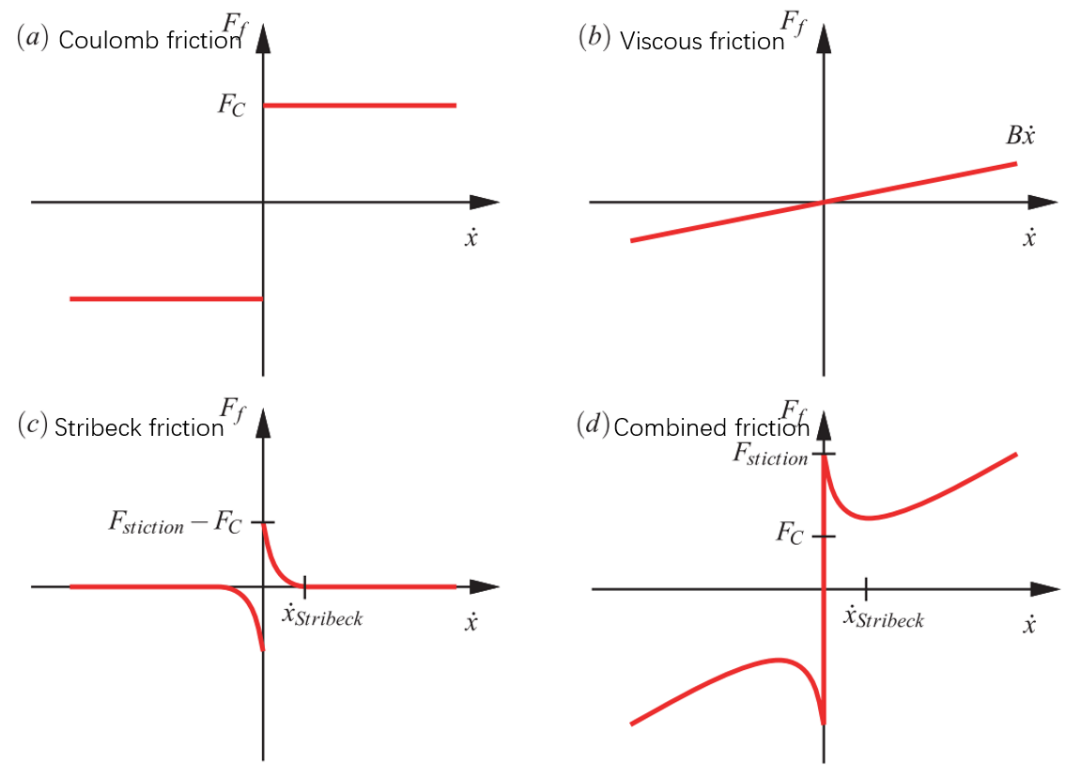

Figure 1 General friction behaviours and combined friction [2].
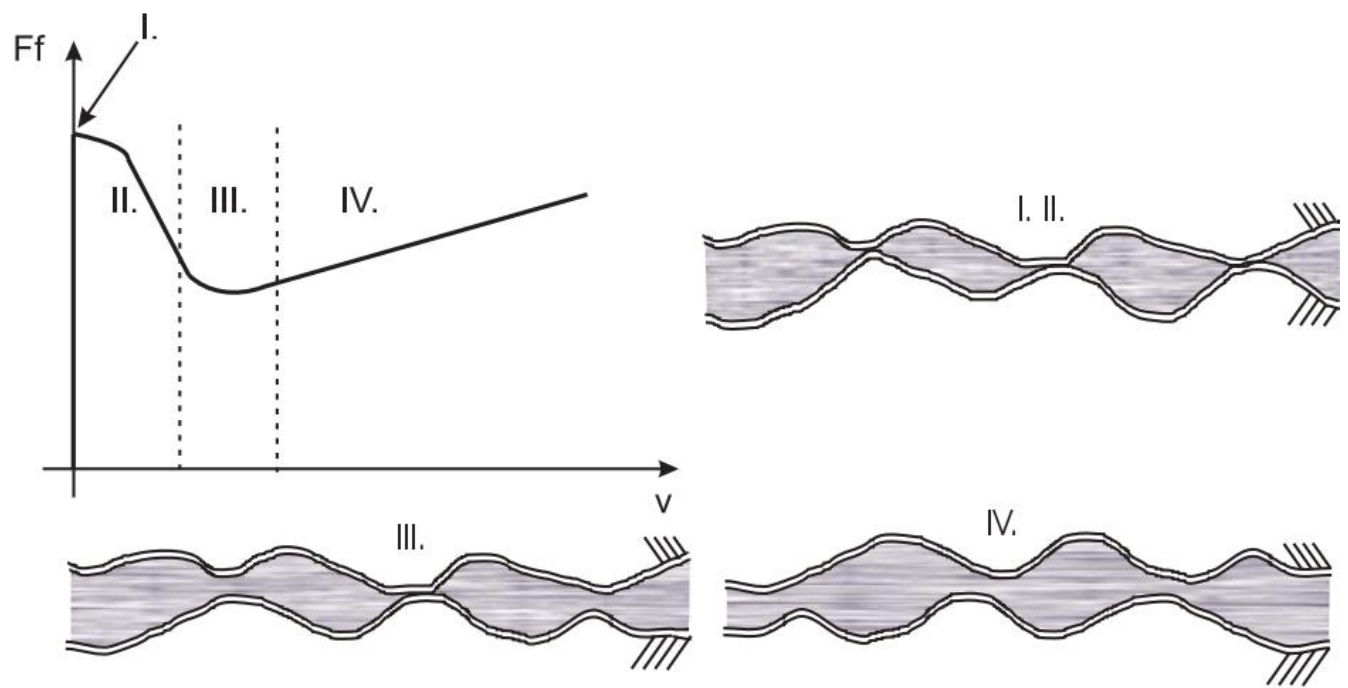

Figure 2 Four regimes of the Stribeck effect [3].

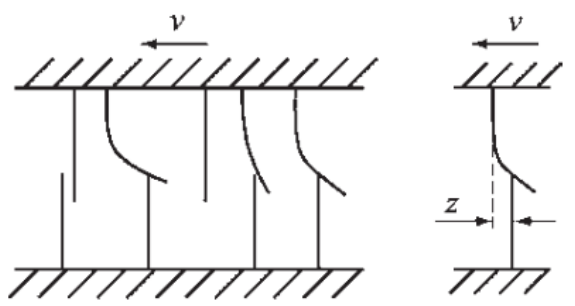

Figure 3 Deformation in the bristle model [4]. 


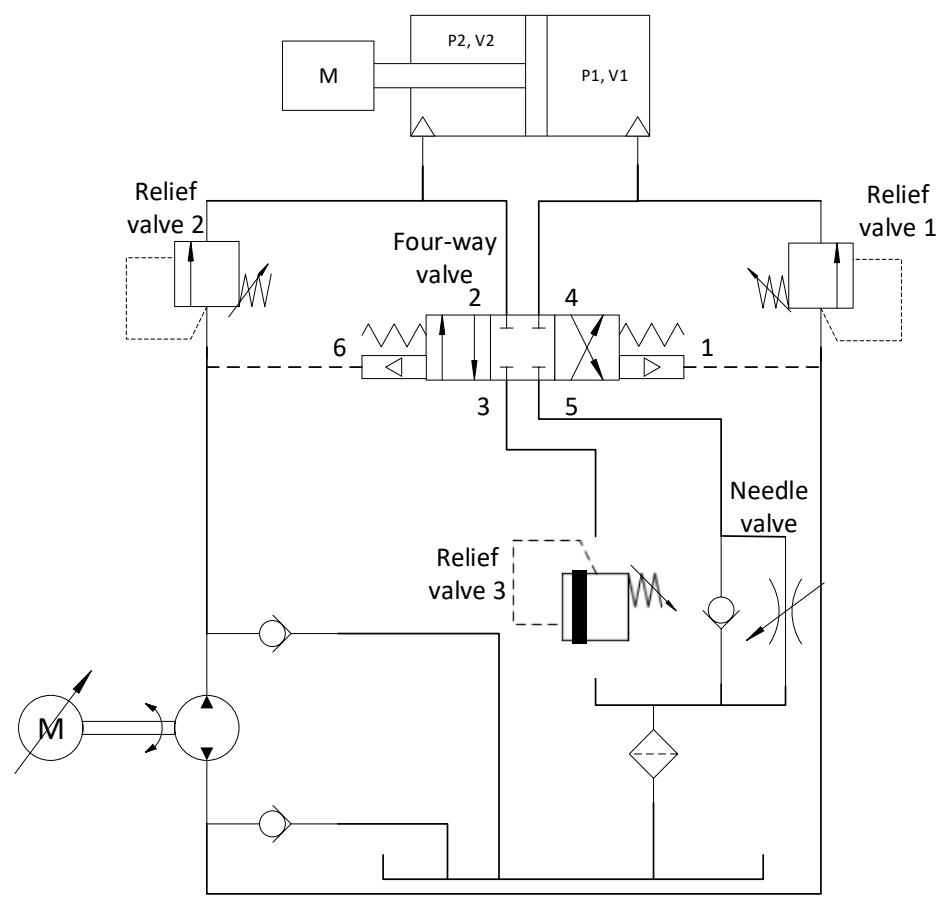

Figure 4 Diagram of the hybrid pump-controlled asymmetric cylinder system.

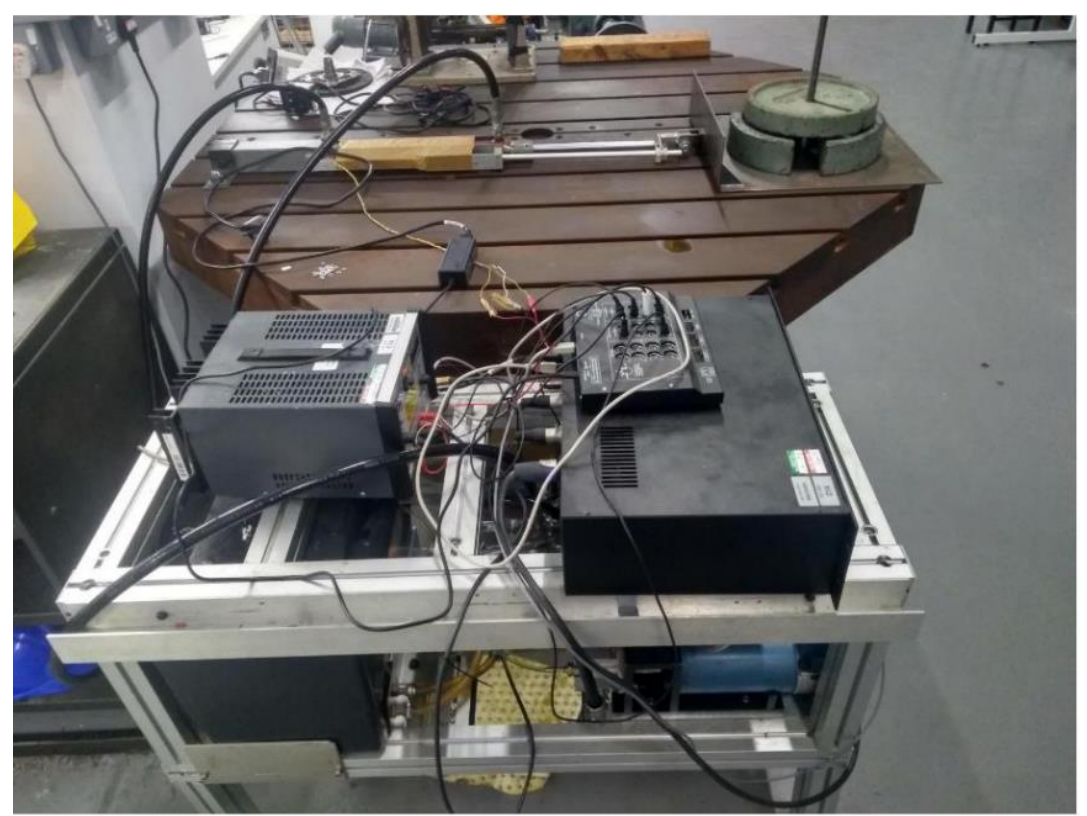

Figure 5 Hybrid pump-controlled asymmetric cylinder drive system. 


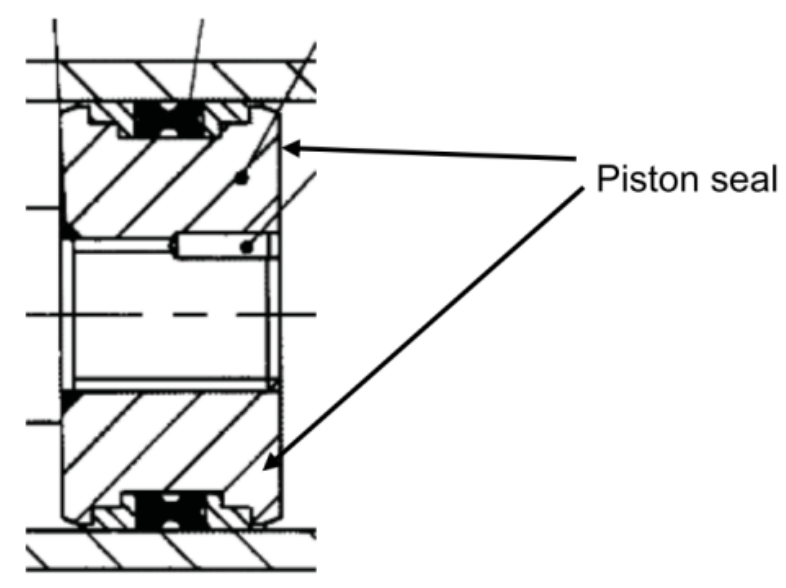

Figure 6 Asymmetric cylinder piston seal [23].

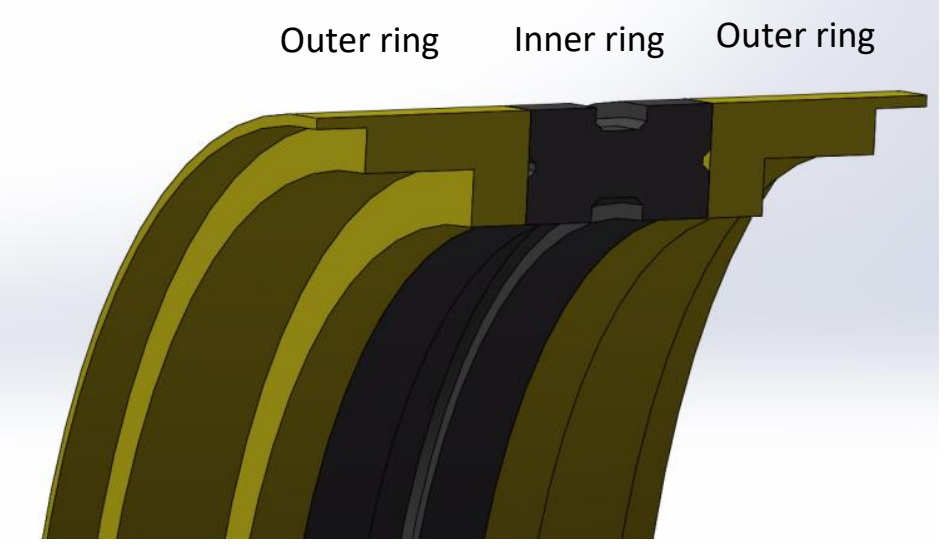

Figure 7 3D section view of the seal 

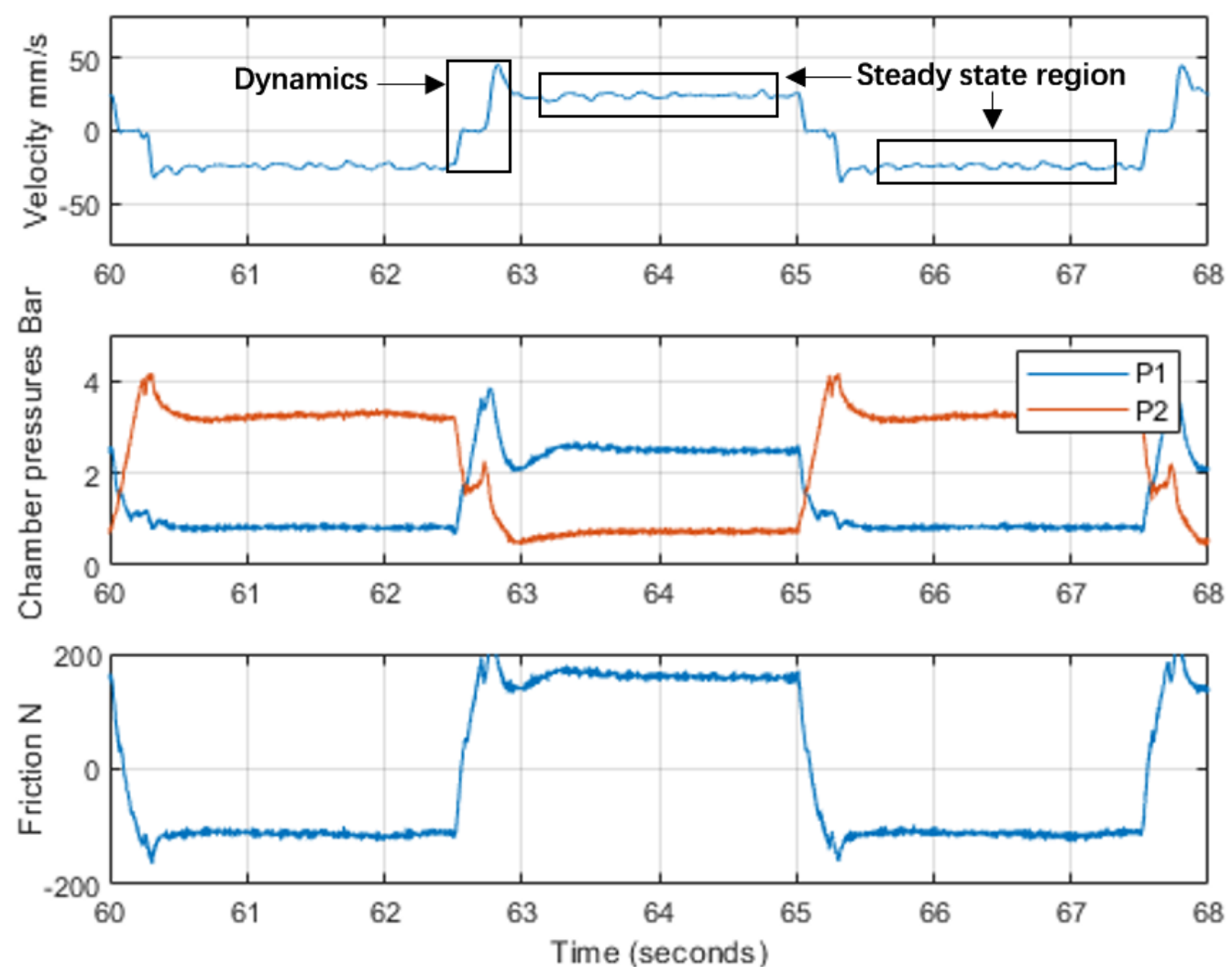

Figure 8 Calculated steady-state friction force for $\pm 25 \mathrm{~mm} / \mathrm{s}$ square wave motion from measured data.

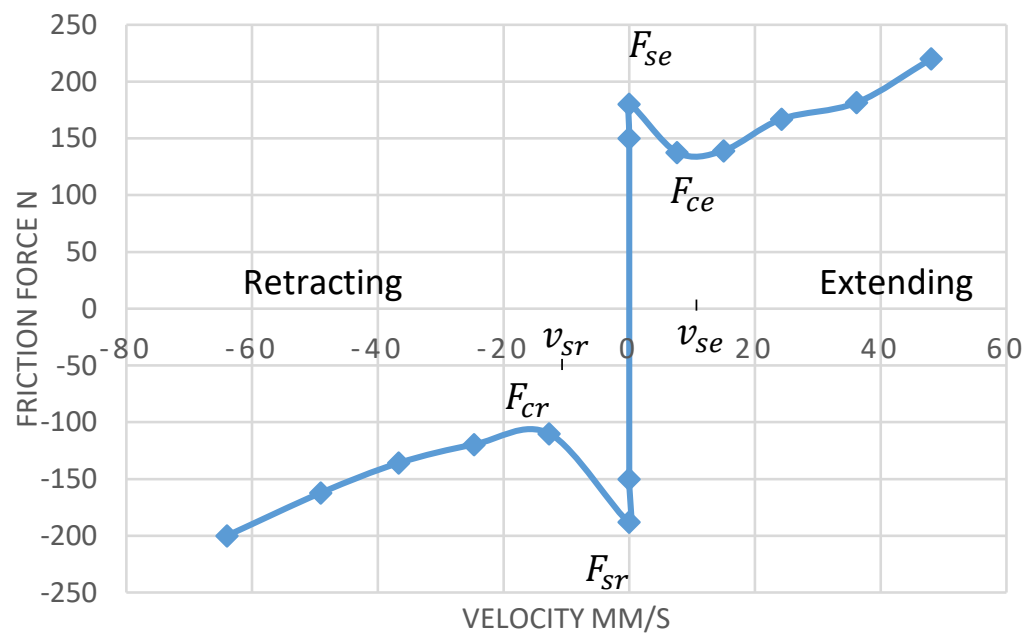

Figure 9 Measured steady-state friction force curve from various square wave tests. 


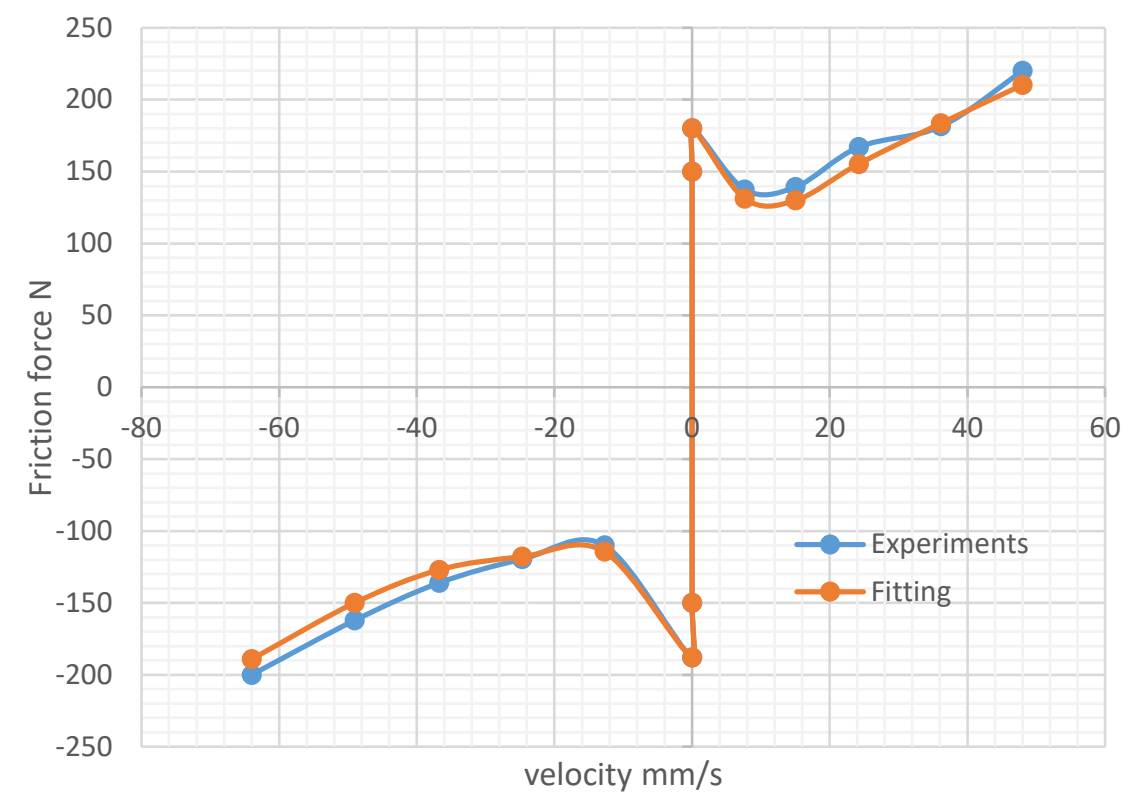

Figure 10 Experimental data vs simulated friction force results at steady state from square wave test.

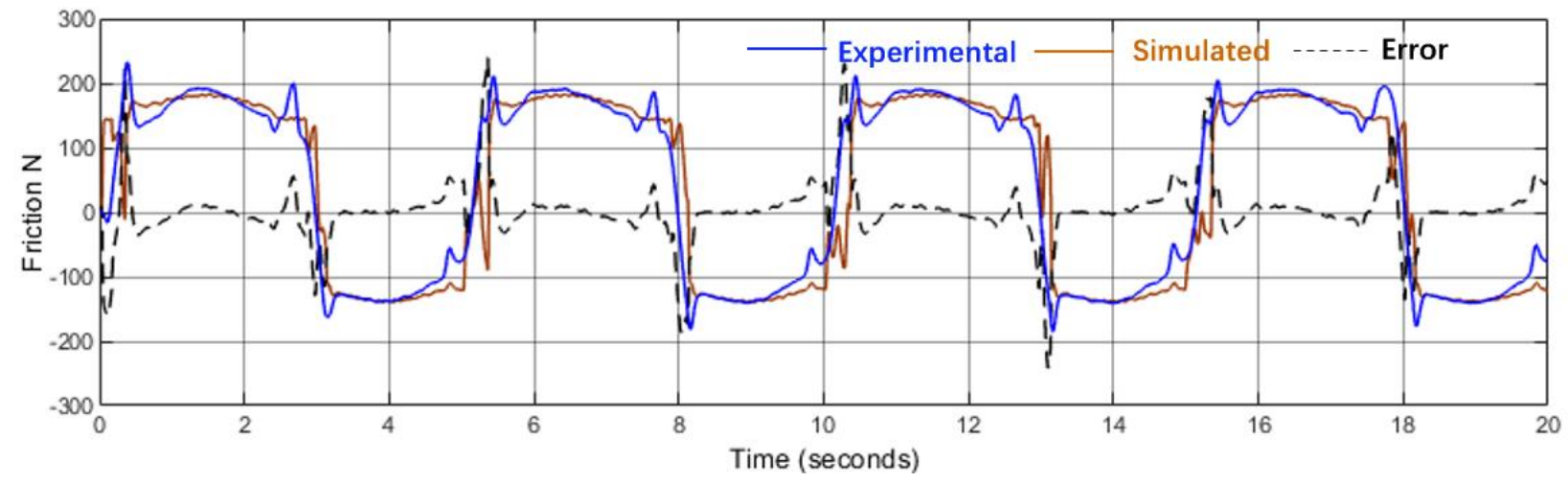

Figure 11 No-added-load experimental dynamic friction vs original LuGre model simulation results $( \pm 50 \mathrm{~mm} / \mathrm{s}$ sine wave $) . R^{2}=0.8938$. 


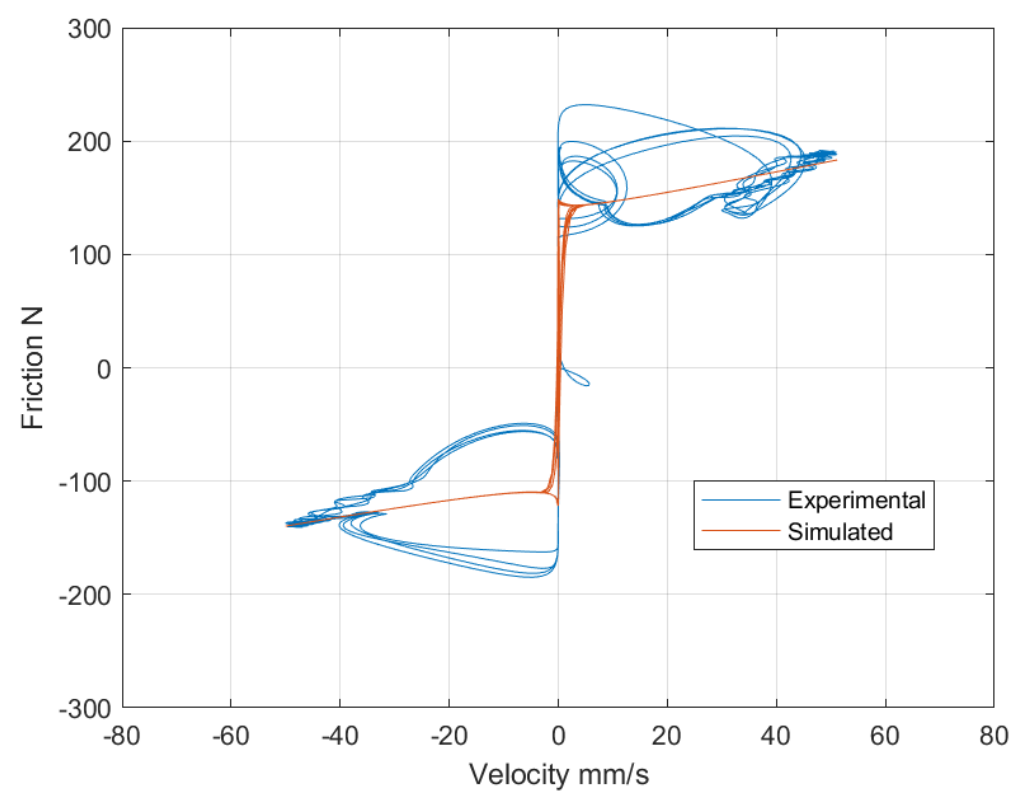

Figure 12 Original LuGre model results compared to experimental results.

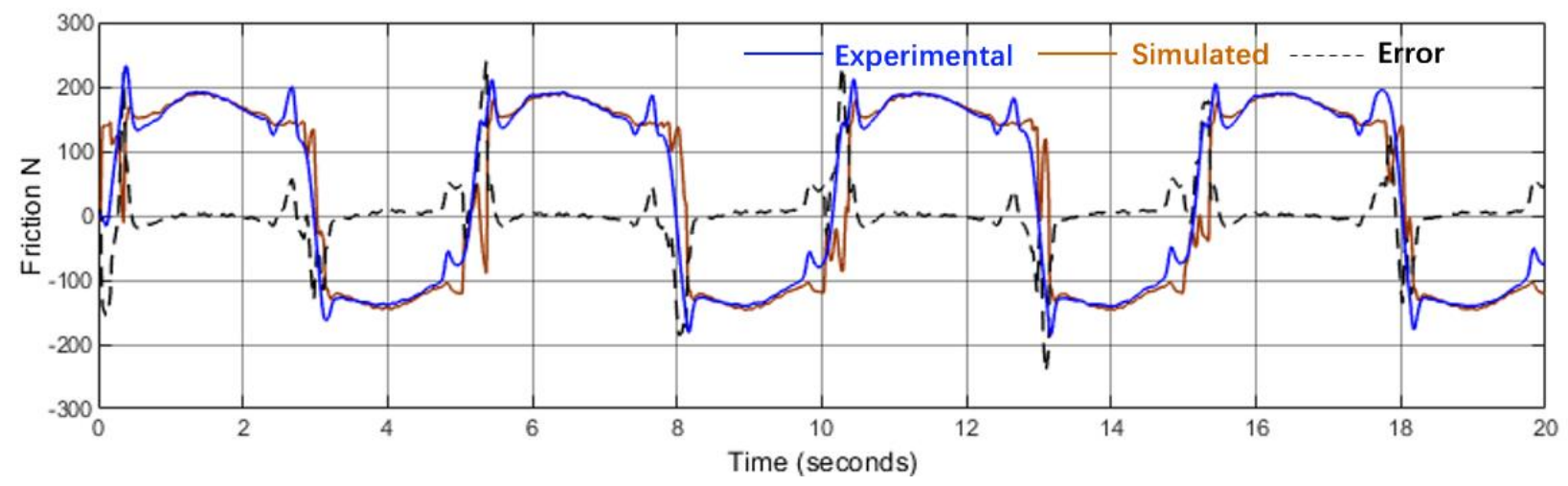

Figure 13 No-added-load experimental dynamic friction vs. new friction model results with a pressure difference term $( \pm 50 \mathrm{~mm} / \mathrm{s}$ sine wave $) . R^{2}=0.8983$. 


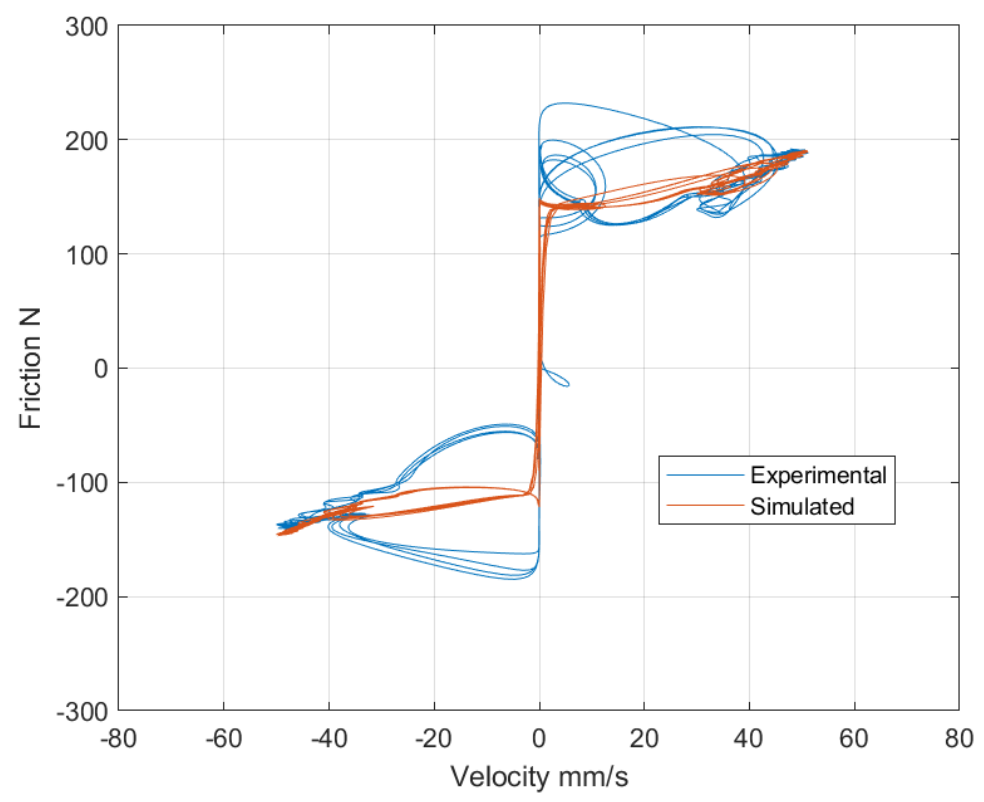

Figure 14 No-added-load experimental friction comparison with the prediction of the model containing a pressure difference term $( \pm 50 \mathrm{~mm} / \mathrm{s}$ sine wave $)$.

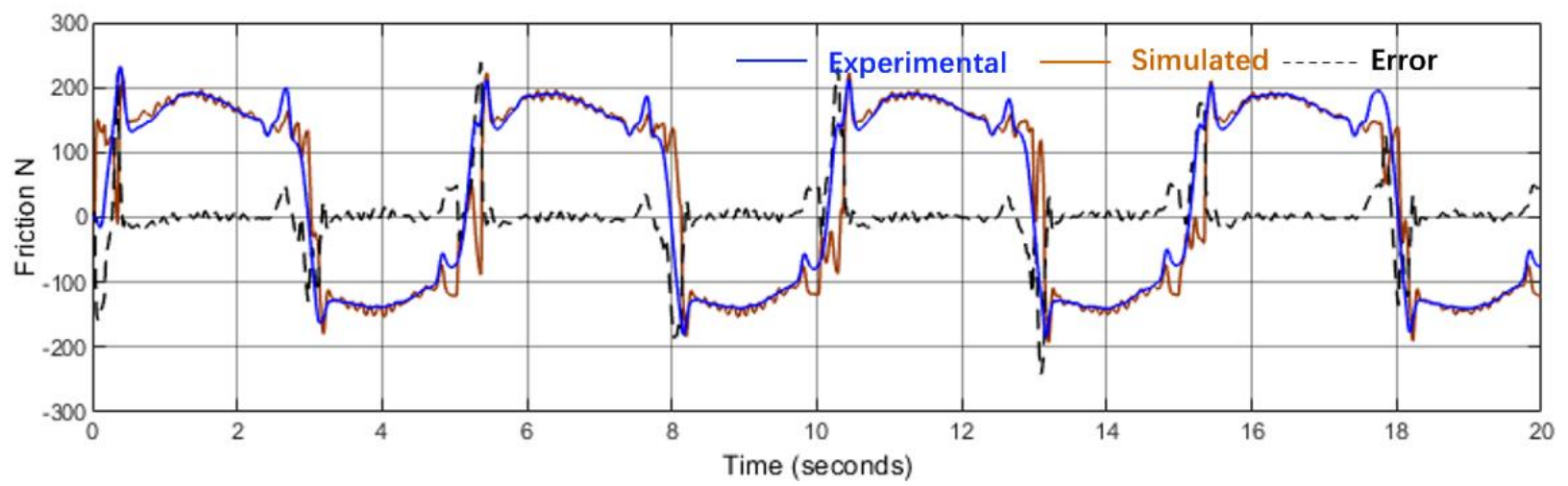

Figure 15 No-added-load experimental friction results vs. new friction model results with pressure and acceleration terms $\left( \pm 50 \mathrm{~mm} / \mathrm{s}\right.$ sine wave). $R^{2}=0.9032$. 


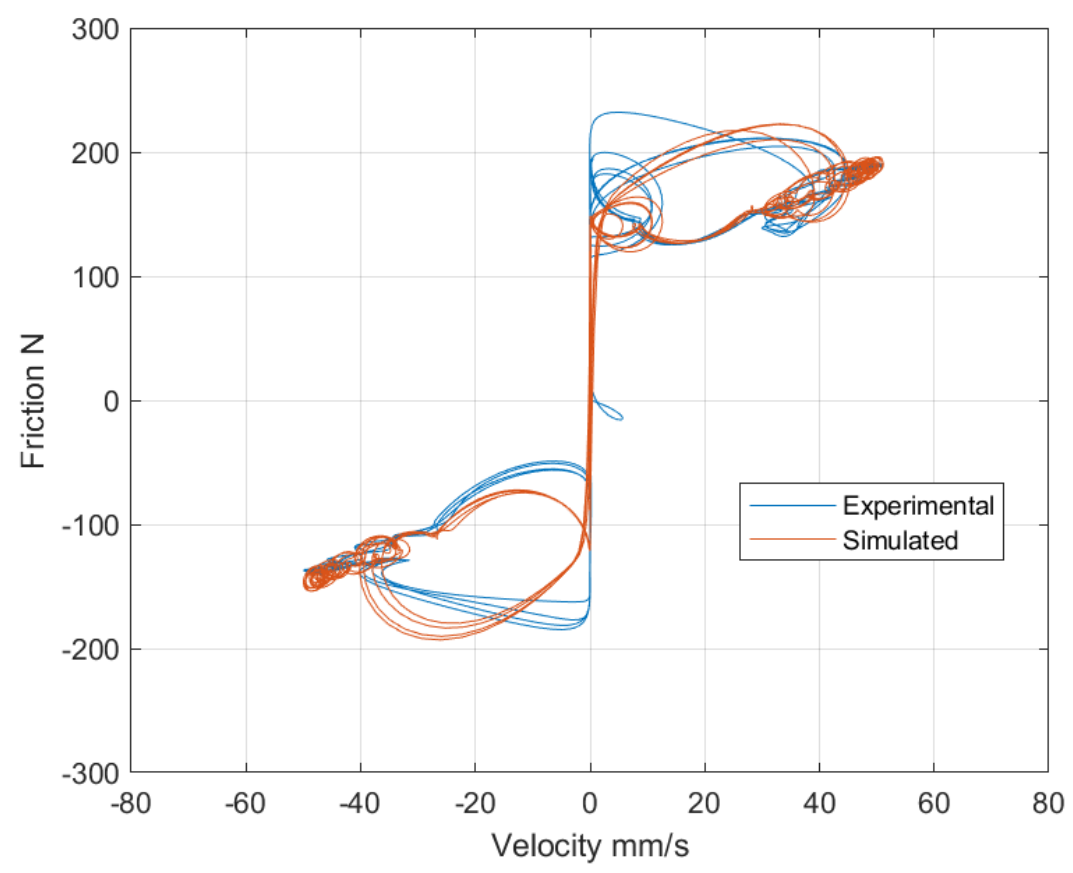

Figure 16 Force vs. velocity curves for the no-added-load experimental data vs. model results with pressure and acceleration terms $( \pm 50 \mathrm{~mm} / \mathrm{s}$ sine wave $)$.

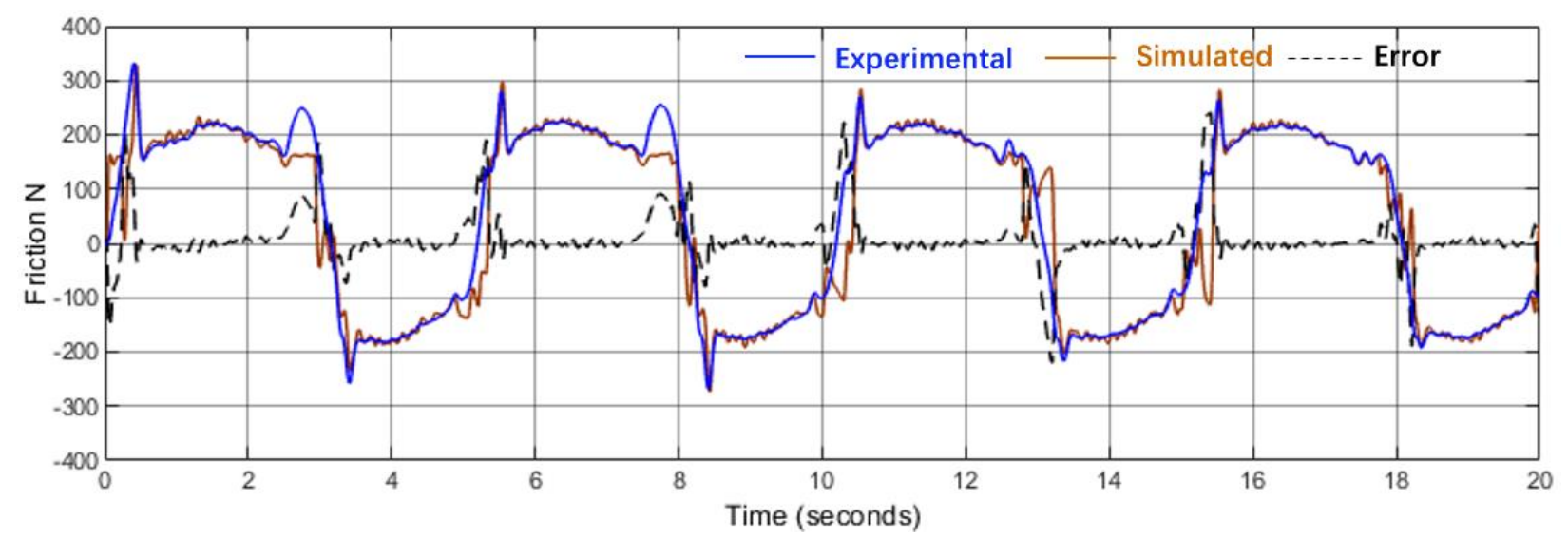

Figure 17 Experimental and model results for the friction force with an added load of $25 \mathrm{~kg}$ ( $\pm 50 \mathrm{~mm} / \mathrm{s}$ sine wave). $R^{2}=0.9231$. 


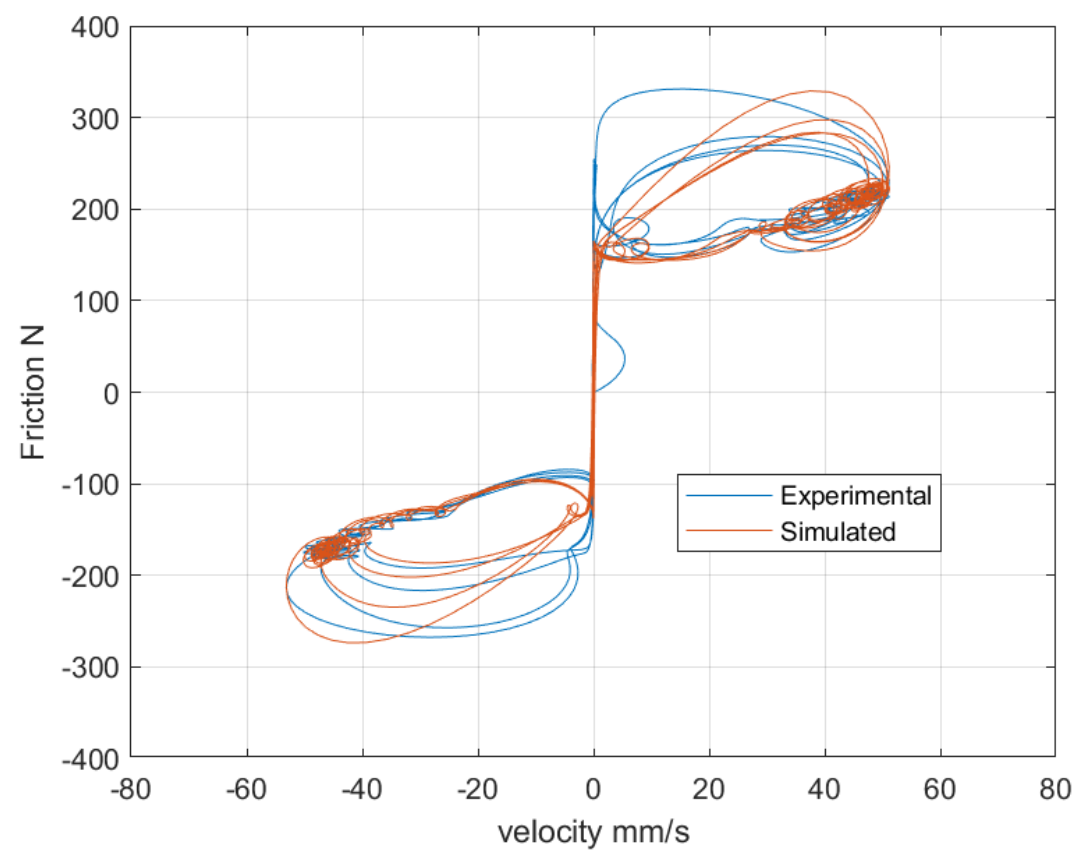

Figure 18 Experimental and friction model results for an added load of $25 \mathrm{~kg}( \pm 50 \mathrm{~mm} / \mathrm{s}$ sine wave).

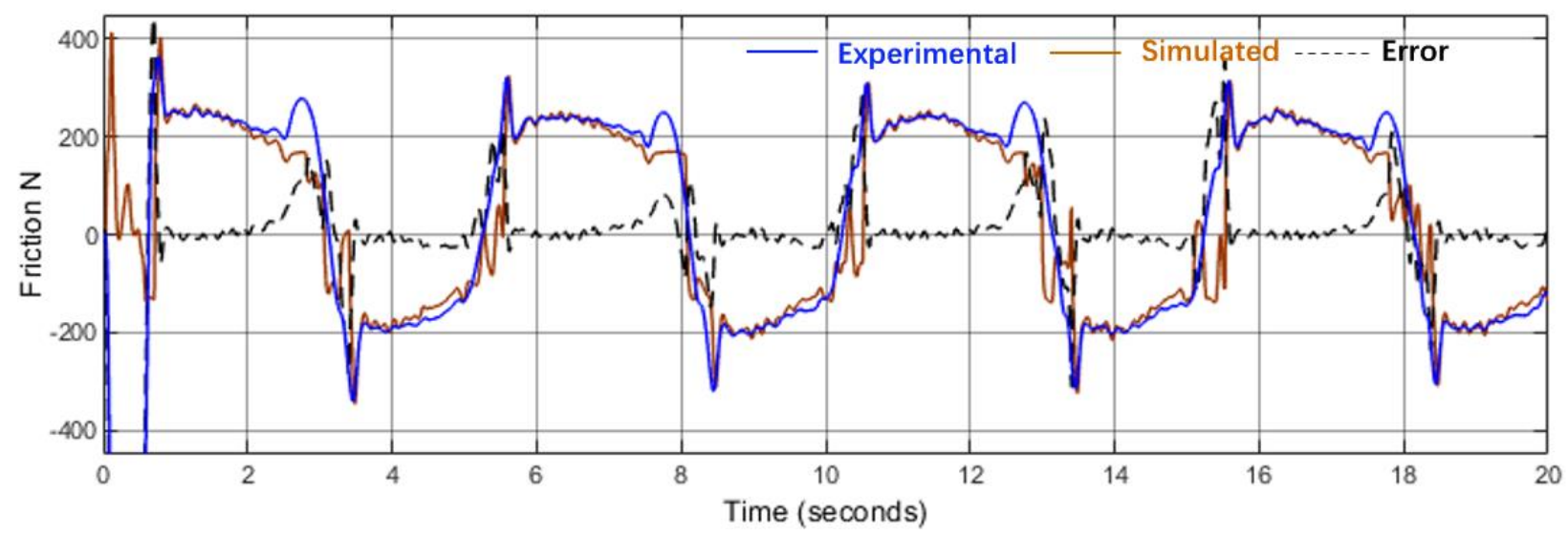

Figure 19 Experimental and model results for the friction force with an added load of $38 \mathrm{~kg}$ $\left( \pm 50 \mathrm{~mm} / \mathrm{s}\right.$ sine wave). $R^{2}=0.5711$ 


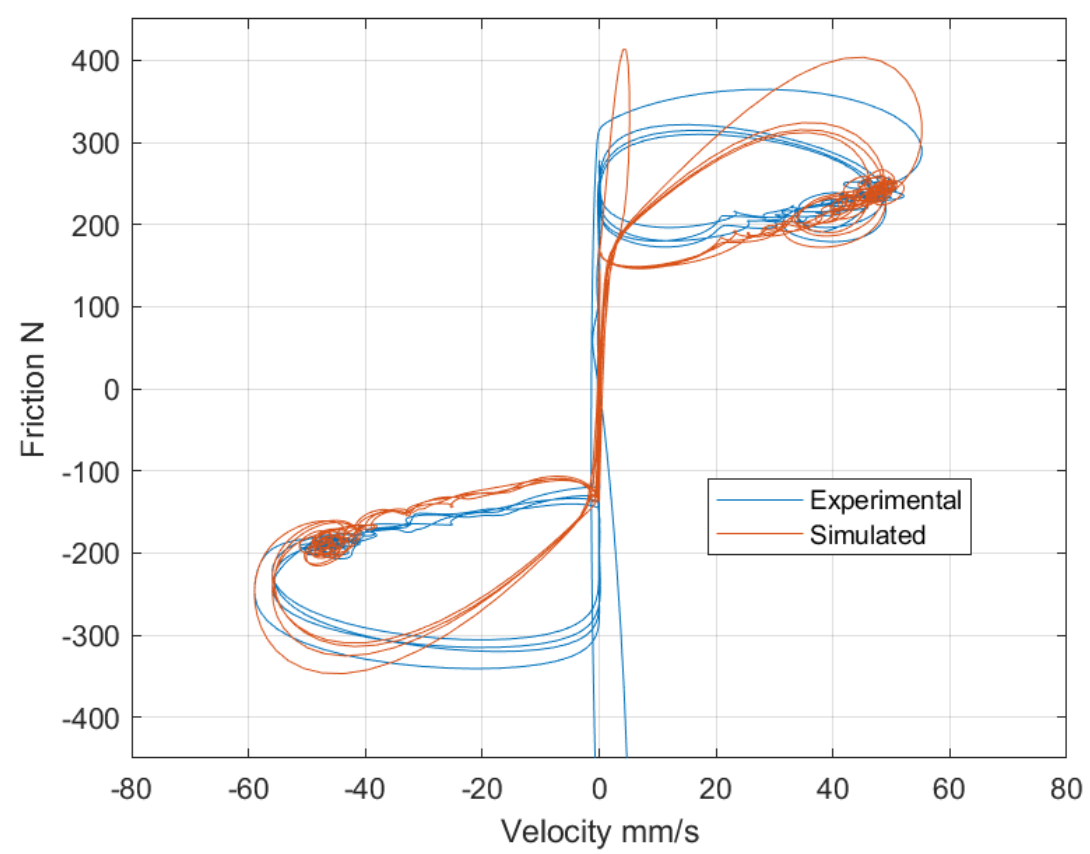

Figure 20 Experimental and friction model results for an added load of $38 \mathrm{~kg}( \pm 50 \mathrm{~mm} / \mathrm{s}$ sine wave).

Table 1 Parameters to be determined for the new friction model

The new friction model parameters 


\begin{tabular}{lll}
\hline \hline Parameter & Unit & Annotation \\
$\sigma_{0}$ & $\mathrm{~N} / \mathrm{m}$ & Stiffness \\
$\sigma_{1}$ & $\mathrm{Ns} / \mathrm{m}$ & Micro-damping \\
$K$ & $\mathrm{~m}^{3} \mathrm{~s} / \mathrm{N}$ & Gain for seal friction \\
$H$ & $\mathrm{~N}^{2} / \mathrm{m}^{5}$ & Acceleration coefficient \\
$F_{C}$ & $\mathrm{~N}$ & Coulomb friction \\
$F_{S}$ & $\mathrm{~N}$ & Stiction friction \\
$v_{S}$ & $\mathrm{~m} / \mathrm{s}$ & Stribeck velocity \\
$\alpha$ & - & Curve constant \\
\hline \hline
\end{tabular}

Table 2 Steady-state measurements

\begin{tabular}{ll}
\hline \hline \multicolumn{2}{l}{ Steady-state friction force test } \\
\hline Velocity & Friction force $\mathrm{N}$ \\
$\mathrm{mm} / \mathrm{s}$ & \\
48.03 & 200 \\
36.18 & 181.5 \\
25 & 167 \\
15 & 139.2 \\
0 & 180 \\
0 & 150 \\
0 & -150 \\
0 & -188 \\
-14.73 & -110 \\
-24.67 & -119.6 \\
-36.71 & -136 \\
-49.05 & -162.2 \\
\hline \hline
\end{tabular}

Table 3 Measured values based on observation

\begin{tabular}{llll}
\hline \hline \multicolumn{3}{l}{ Measured values from observation } \\
\hline Parameter & Unit & Extending & Retracting \\
$F_{C}$ & $\mathrm{~N}$ & 110 & -80 \\
$F_{S}$ & $\mathrm{~N}$ & 180 & -188 \\
$v_{S}$ & $\mathrm{~mm} / \mathrm{s}$ & 10 & -10 \\
\hline \hline
\end{tabular}

Table 4 Parameter values obtained from CFTOOL in Matlab

\begin{tabular}{llll}
\hline \hline \multicolumn{3}{l}{ Curve fitting values } & \\
\hline Parameter & Unit & Extending & Retracting \\
\hline \hline
\end{tabular}




\begin{tabular}{llll}
\hline \hline$\alpha$ & $/$ & 0.1087 & 0.1138 \\
$K$ & $\mathrm{~m}^{3} \mathrm{~s} / \mathrm{N}$ & $2.5 \times 10^{-8}$ & $4 \times 10^{-9}$ \\
\hline \hline
\end{tabular}

Table 5 Initial guess of $\sigma_{0}$ and $\sigma_{1}[21]$

\begin{tabular}{lll}
\hline \hline \multicolumn{3}{l}{ Initial guess values } \\
\hline Parameter & Unit & Value \\
$\sigma_{0}$ & $\mathrm{~N} / \mathrm{m}$ & $1 \times 10^{7}$ \\
$\sigma_{1}$ & $\mathrm{Ns} / \mathrm{m}$ & 0.1 \\
\hline \hline
\end{tabular}

Table 6 Adjusted values of $\sigma_{0}$ and $\sigma_{1}$

\begin{tabular}{lll}
\hline \hline \multicolumn{2}{l}{ Adjusted values } \\
\hline Parameter & Unit & Value \\
$\sigma_{0}$ & $\mathrm{~N} / \mathrm{m}$ & $3 \times 10^{7}$ \\
$\sigma_{1}$ & $\mathrm{Ns} / \mathrm{m}$ & 0.1 \\
\hline \hline
\end{tabular}

Table 7 Parameters of the new friction model for the test rig

\begin{tabular}{llll}
\hline \hline \multicolumn{3}{l}{ Parameters values for no added load test rig } \\
\hline Parameter & Unit & Extending & Retracting \\
$F_{C}$ & $\mathrm{~N}$ & 110 & -80 \\
$F_{S}$ & $\mathrm{~N}$ & 180 & -188 \\
$v_{S}$ & $\mathrm{~mm} / \mathrm{s}$ & 10 & -10 \\
$\alpha$ & $/$ & 0.1087 & 0.1138 \\
$K$ & $\mathrm{~m}^{3} \mathrm{~s} / \mathrm{N}$ & $2.5 \times 10^{-8}$ & $4 \times 10^{-9}$ \\
$\sigma_{0}$ & $\mathrm{~N} / \mathrm{m}$ & $3 \times 10^{7}$ & $3 \times 10^{7}$ \\
$\sigma_{1}$ & $\mathrm{Ns} / \mathrm{m}$ & 0.1 & 0.1 \\
$H$ & $\mathrm{~N}^{2} \mathrm{~s} / \mathrm{m}^{4}$ & $3.05 \times 10^{9}$ & $9 \times 10^{9}$ \\
\hline \hline
\end{tabular}

Table 8 Stiction force $F_{S}$ and Coulomb force $F_{C}$ for $25-\mathrm{kg}$ load

\begin{tabular}{llll}
\hline \hline \multicolumn{3}{l}{ Added load 25 kg } & \\
\hline Parameter & Unit & Extending & Retracting \\
$F_{C}$ & $\mathrm{~N}$ & 120 & -90 \\
\hline \hline
\end{tabular}




\begin{tabular}{|c|c|c|c|}
\hline $\bar{F}$ & $\mathrm{~N}$ & 200 & -190 \\
\hline \multicolumn{4}{|c|}{ Table 9 Stiction force $F_{S}$ and Coulomb fo } \\
\hline \multicolumn{4}{|c|}{ Added load 38 kg } \\
\hline Parameter & Unit & Extending & Retracting \\
\hline$F_{C}$ & $\mathrm{~N}$ & 122 & -80 \\
\hline$F_{S}$ & $\mathrm{~N}$ & 205 & -188 \\
\hline
\end{tabular}

